\title{
Post-Keratoplasty Glaucoma
}

\author{
COLIN M KIRKNESS, CON MOSHEGOV
}

London

\section{Summary}

The incidence of post-keratoplasty glaucoma remains at about $30 \%$ of all grafts performed. Aphakic eyes, particularly those after intracapsular extraction, the elderly, traumatised eyes and eyes undergoing repeat corneal grafts appear to be at greatest risk. This paper also reviews the mechanisms and treatment of post keratoplasty glaucoma.

In the days before the introduction of the operating microscope and atraumatic fine gauge sutures, wound leaks were common after penetrating keratoplasty. Eyes which survived the first few days often had anterior synerchiae, both peripherally in the angle of the anterior chamber and also more centrally to the graft host interface. A frequent consequence was intractable glaucoma. Microsurgery rectified many of the peroperative technical problems. The problem of glaucoma, developing following keratoplasty, did not cease, however, nor did it abate. Irving ${ }^{1}$ in 1969 , drew attention to the problem and the difficulties encountered in the assessment of raised intraocular pressure in many of these patients with corneal grafts. Applanation tonometry may be difficult because of severe astigmatism in the early (or even late) post-operative period, and also when the graft is $7-7.5 \mathrm{~mm}$ in diameter, a size which causes the fluorescein meniscus or tonometer mires to be thick and inaccurate. Large degrees of astigmatism cause the mires to be distorted. The Mackay-Marg tonometer has been recommended but has failed to find widespread use, perhaps due to the difficulty in interpreting the tracing. (Fig. 1)

If pressure readings can be difficult, then recording of the visual field, is even more so. Susceptible patients (vide infra) are frequently aphakic, and this taken together with the swinging astigmatism may render field recording

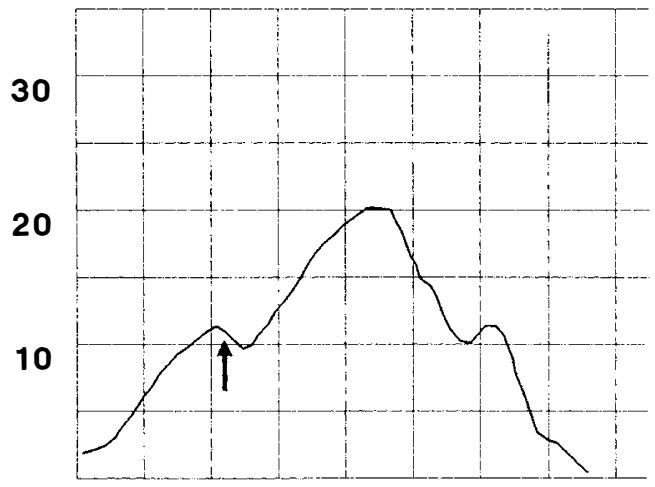

Fig 1. An ideal tracing from a Mackay-Marg tonometer. The arrow shows the value equal to the intraocular pressure.

significantly inaccurate so that comparisons from one date to another may be invalid. Disc assessment too is inaccurate for regular monitoring since it will only reveal gross changes. Photogrammetry of the optic disc is an exciting prospect for the near future. Work is also in progress studying electrophysiological parameters in the detection of nerve fibre loss. ${ }^{2}$

Post-keratoplasty glaucoma (PKPG) is thus amongst the most difficult of the glaucomas to monitor. In addition to the damage that the raised IOP may do to the optic nerve, prolonged elevation of the IOP may be damaging to donor endothelium. ${ }^{3}$ This review seeks to describe the significance of the problem of PKPG in corneal

From Corneal Clinic, \& Department of Clinical Ophthalmology, Institute of Ophthalmology, Moorfields Eye Hospital, City Road, London

Correspondence to: Mr. C M Kirkness, FRCS, Department of Clinical Ophthalmology, Institute of Ophthalmology, Moorfields Eye Hospital, City Road, London ECIV 2PD 
graft surgery, and to discuss the means of dealing with it.

\section{Mechanisms}

The major group of patients in whom pressure problems are encountered throughout the history of modern corneal grafting remains those with aphakic bullous keratopathy, and it is towards this group that most effort has been directed in order to understand the mechanisms involved. Arguing that the pressure rise found in aphakic grafts related to the change in geometry of the anterior chamber, Olson and Kaufman ${ }^{4}$ suggested, that with appropriate manipulation of the host and donor button sizes, it might be possible to avoid PKPG altogether. There followed a series of papers exploring these mechanisms. Zimmerman and co-workers using perfusion studies on cadaver eyes demonstrated that a corneal graft performed on a phakic eye did not appreciably alter the outflow facility when the host bed and donor were trephined to the same size, but in aphakic eyes the outflow facility was reduced by an average of $37 \%$, when midstromal suturing was employed, and not when through and through suturing was used. ${ }^{5}$

The donor button size was also thought to be important and Zimmerman produced evidence to suggest that, in the aphakic patient, at least, the use of a donor button trephined with a trephine $0.5 \mathrm{~mm}$ larger than that used for the host bed reduced the incidence of PKPG. The effect was more obvious when a $7.5 \mathrm{~mm}$ trephine was used. ${ }^{6}$ Unfortunately, no account was taken of the real difference in size of excised buttons which may be produced by a change in intraocular pressure of the eye, or different pressures used when trephining or the differences which may be encountered due to varying corneal rigidity. It is quite possible to produce a corneal button at least $1 \mathrm{~mm}$ in diameter larger than the nominal trephine size by altering these parameters (personal observation).

Olson and Kaufmann produced an elegant mathematical model demonstrating, theoretically, how outflow facility could be decreased following keratoplasty. ${ }^{7,8}$ They suggested that the important adverse factors were tight suturing, long bites of the individual sutures, "Larger trephine sizes" ( 8.5 donor into $8 \mathrm{~mm}$ host bed), graft-host disparity when the donor is smaller than the host, and increased peripheral corneal thickness. To fit the observed situation that it was only the aphakic eye that suffered, they invoked the concept, first propounded by Zimmerman, ${ }^{5}$ of trabecular collapse. The trabecular system was postulated to require the posterior fixation normally associated with an intact lens-ciliary body system. In aphakia the trabeculum relaxes and when the angle is compressed following grafting the outflow is compromised. Although this description fitted the recognised factors rather well, it is almost certainly an over-simplification but the principles that were implied are worthy of consideration.

Observation of patients over the extended postoperative period demonstrated that not all the IOP rise is temporarily directly related to the perioperative period. In these patients some additional or different mechanism must be involved. Lass suggested that PKPG could be associated with the development of fine peripheral anterior synechiae after keratoplasty. ${ }^{9}$ This may be progressive and has been the rationale for iris suturing during keratoplasty to limit synechial formation. ${ }^{10}$ While synechial formation is also appealing as a description of the mechanism, it cannot explain all PKPG but in combination with Olson and Zimmerman's ideas, it may explain a great many situations. It is disappointing that after such elegant theoretical work there was so little clinical substantiation. Only one retrospective series lends support to these theories. Bourne ${ }^{11}$ found, in the short term, that oversized (by nominal trephine size) buttons produced better "control" than same size buttons in eyes with no pre-keratoplasty glaucoma. Where there was pre-existing glaucoma, then button size did not appear to have significant influence. In a similar study Perl ${ }^{12}$ was unable to demonstrate any protection against the development of glaucoma by using a donor cut with a trephine 0.5 $\mathrm{mm}$ larger than the host bed. Again this study was based on trephine size and not the size of the excised tissue. Olson ${ }^{13}$ emphasised this point in the discussion of Perl's paper ${ }^{12}$ and at the same time pointed out that analysis of Perl's figures did show differences between those who had the same size graft and those who had a slightly larger one, claiming that there was some protective role for the larger graft.

As corneal surgical techniques advance, and more and more severely disorganised eyes are salvaged, then it is likely that glaucoma will become a more common problem. Kirkness ${ }^{14}$ has recently reported a series of patients undergoing keratoplasty following suppurative keratitis, per- 
Table I Incidence of raised IOP (>21mmHg), according to indication for keratoplasty

\begin{tabular}{lccc}
\hline Diagnosis & Number of PKs & $\begin{array}{c}\text { Number with } \\
\text { raised IOP }\end{array}$ & $\%$ \\
\hline Keratoconus & 99 & 12 & 12 \\
Bullous keratopathy & 33 & 20 & 61 \\
Fuchs' dystrophy & 35 & 13 & 37 \\
Stromal dystrophy & 22 & 5 & 23 \\
Previous PK & 29 & 13 & 45 \\
HSK & 25 & 5 & 20 \\
Keratitis (IK) & 31 & 7 & 23 \\
Trauma & 10 & 6 & 60 \\
Chemical burns & 3 & 0 & 0 \\
Buphthalmos & 5 & 4 & 80 \\
Others (all small sample size) & 16 & 6 & 37.5 \\
\hline
\end{tabular}

$\mathrm{HSK}=$ herpes simplex keratitis, $\mathrm{IK}=$ interstitial keratitis, $\mathrm{PK}=$ penetrating keratoplasty

foration being the main indication for surgery in 14 out of 23 eyes. There is a suggestion that the longer the eye was perforated before surgery, the greater was the likelihood of significant angle damage either from the development of peripheral anterior synechiae or from the associated severe intraocular inflammation. Nearly one third of all patients in the series (7/23) developed raised IOP requiring treatment, following keratoplasty. In a similar series of emergency grafts, but where there was no suppuration, four out of 13 perforations were associated with PKPG. (Unpublished data). Again there was a trend suggesting that the longer the interval between perforation and keratoplasty, the greater was the risk of glaucoma, although the numbers are too small to produce valid statistical significance.

In most commentaries on PKPG, suggestions are made that manipulation of steroid therapy may help reduce intraocular pressure. ${ }^{15}$ In fact, patients who have had corneal grafts generally need steroids as prophylaxis against graft rejection and also to treat postoperative inflammation. Steroid reduction or withdrawal is not a realistic management option in the majority of these cases.

\section{Incidence}

Since the work of Zimmerman, Olson and Kaufman, ${ }^{1,4-8}$ there has been little description of the incidence of PKPG. It is not known whether modern intraocular techniques have helped alleviate the problem or whether more advanced surgery has brought more patients into the "at risk areas".

The authors retrospectively surveyed a series of patients attending the Corneal Clinic at Moorfields Eye Hospital who had undergone penetrating keratoplasty between $1978-85$; a minimum follow-up of 12 months, with regular assessment was required. Patients who were lost to follow-up or returned to another (referring) ophthalmologist were excluded. With these exclusions 305 patients were identified. Although great care was taken in the accurate assessment of donor button and host bed size, during keratoplasty, there was no deliberate policy of routinely oversizing trephines used for aphakic grafts. The majority of donors were moist chamber stored.

Glaucoma was defined as intraocular pressure greater than $21 \mathrm{mmHg}$ with or without evidence of disc cupping or field loss. Ages ranged from 1-89 yrs at the time of surgery. The overall breakdown of diagnosis and raised pressure is shown in Table I. Data were analysed by Chi squared test in the case of the 3 binominal sample and the Chi squared test with Yates' correction when the data could be arranged in $2 \times 2$ contingency tables.

Only $5 \%$ of all eyes had raised IOP that responded to manipulation of steroid therapy. All of these cases were among the $10 \%$ that developed glaucoma more than 2 months postoperatively. It is interesting to note that Krupin and Waltman found that $6 \%$ of the population develop raised IOP after 6 weeks of topical therapy. ${ }^{16}$ Overall, 91 eyes, $30 \%$, were found to have raised pressure $(>21 \mathrm{mmHg})$. Eighty eyes were or became aphakic. (Table II). There was a significantly higher incidence of glaucoma in aphakic or pseudophakic patients compared to phakic, $p<0.001$. There was no significant difference between aphakic and 
Table II Distribution according to the phakic state

\begin{tabular}{|c|c|c|c|}
\hline & Phakic & Aphakic & Pseudophakic \\
\hline \multirow[t]{2}{*}{ Raised IOP } & $\begin{array}{c}207 \\
41 \\
(20 \%)\end{array}$ & $\begin{array}{c}80 \\
43 \\
(53 \%)\end{array}$ & $\begin{array}{c}18 \\
7 \\
(39 \%)\end{array}$ \\
\hline & Phakic & $\begin{array}{c}\text { Aphakic or } \\
\text { Pseudophakic }\end{array}$ & \\
\hline$<45$ yrs & 149 & 14 & \\
\hline Raised IOP & 21 & 8 & Total 29 \\
\hline$>45$ yrs & 58 & 84 & \\
\hline Raised IOP & 21 & 41 & Total 62 \\
\hline
\end{tabular}

pseudophakic patients and they will not be differentiated further and both groups will be referred to as aphakic. There were, however, too few patients in the group who had had posterior chamber lens implants inserted to allow differentiation between this group and other cases of pseudophakia.

Overall, in the younger age group ( $<45 \mathrm{yrs})$, $18 \%$ developed raised IOP, whereas $44 \%$ of those over 45 years did so. Comparing the phakic and aphakic patients, in the aphakic group, $57 \%$ of the younger and $49 \%$ of the older groups developed raised pressure; but of the phakic subdivision, $14 \%$ of the younger and $36 \%$ of the older groups had raised IOP. (Table III). There was a significantly higher incidence of pressure problems in the younger group that had had lens surgery compared to those who had not, $\mathrm{p}<0.002$. In the older group the difference was not significant $\mathrm{p}>0.1$. There was, however, a significantly higher incidence of raised IOP in the older group of phakic patients compared to the younger phakic group, $\mathrm{p}>0.001$.

Two other groups appeared to be at risk. In those undergoing keratoplasty for trauma the incidence was significantly higher at $p=0.05$, than others and in the group undergoing repeat corneal grafts compared to first grafts, $p=0.05$. These data support the statements of Kaufman and others that aphakia presents a higher risk of PKPG, but the risk of developing PKPG after traumatic keratoplasty, and regraft has not received wide comment. The risk in old age may represent an association with decreased outflow of the eye and increased risk of glaucoma in the general popula- tion with age, ${ }^{17}$ and its susceptibility to angle distortion. The incidence of steroid responders is very close to that of the general population but it is possible that more are concealed in the groups of patients in whom it was not possible to alter the topical steroid regimes. Thirty eyes in the study had some degree of pressure elevation which had been controlled, prior to surgery. Of these, the majority $(60 \%)$ required more therapy, or surgery, eventually, in 3 cases, but, paradoxically 3 cases required less therapy than had been needed pre-operatively.

The incidence of PKPG seems remarkably constant compared to that of a decade earlier although there appears to be a widening range of predisposing factors. It will be interesting to observe in the near future whether the use of posterior chamber intraocular lens implants has any influence on the incidence of glaucoma in patients subsequently undergoing keratoplasty.

\section{Management of Established Postkeratoplasty Glaucoma \\ Medical}

The mainstay of medical control of PKPG has traditionally been acetazolamide partly because of its efficacy and partly because it is taken systemically and therefore obviates the risk of toxicity from all topical applications to the graft epithelium. More recently the use of beta-blockers such as timolol have become more widespread, although it has been noted that there is often associated punctate epitheliopathy in the graft epithelium following their use. ${ }^{18}$ Pilocarpine or phospholine iodide may be used with caution but 
are less likely to produce beneficial reduction of IOP in eyes which have extensive secondary angle closure. Miotics may also occasionally promote a low grade anterior segment inflammation which may promote allograft rejection episodes. Neutral adrenaline or dipivefrin are to be avoided in the susceptible groups because of the risks of cystoid macular oedema in aphakes and the danger of herpetic recrudescence in herpes simplex keratitis.

\section{Surgical}

Van Meter et al have recently described, for the first time, the use of laser trabeculoplasty (LTP) in PKPG. ${ }^{19}$ Although the series is relatively small they were able to make useful comments. The patients were either aphakic or pseudophakic, and nine had had intracapsular lens extraction. Most of the eyes had extensive peripheral anterior synechiae thus limiting the availability of angle for LTP. Nevertheless a reduction in intracular pressure was achievable in eight of the 10 patients but in seven of the 10 patients it was not possible to reduce antiglaucoma medication.

The technique appears to be safe as far as the graft endothelium is concerned and merits consideration early in the management of PKPG, and where there is not widespread secondary angle closure. No data exist on the success of trabeculectomy in keratoplasty. In general terms, it might be expected that, where the conjunctiva was not scarred, then the success should be no worse than in a similar non-grafted eye. That may, however, be an oversimplification of the situation. Anecdotal experience of many surgeons is that trabeculectomy is a far from satisfactory technique to use. If one considers, however, the nature of the groups at risk (viz aphakia, trauma, postsuppurative keratitis), it is clear that many have extensive anterior segment disorganisation including scarred conjunctivae, situations where trabeculectomy might be expected to do badly in any case. The surgical alternatives once trabeculectomy has failed are limited. Trabeculectomy may be repeated but with rapidly diminishing prospects of success. Cylodialysis has been shown by Casey ${ }^{20}$ to have a limited chance of success. At the very best only 22 out of 100 cases were within a broad definition of success. Cyclocryotherapy has been used as the surgical procedure of choice in different and advanced cases. Binder ${ }^{21}$ showed that it could be useful, but his series had a relatively short follow-up of
20 months and he does not state the length of time that the patients were successfully controlled. In addition, there were a large number of serious complications including failed grafts, cyclitic membranes, cystoid macular oedema, vitreous haemorrhage and phthisis bulbi. The technique, nevertheless, was widely used. Perhaps the fact that it is not an intraocular procedure, helped encourage its use. Lemp ${ }^{22}$ had previously shown a high failure of grafts after any form of intraocular surgery. The rationale behind cyclocryotherapy is unsatisfactory. It seems illogical to treat a condition where the basic mechanism is an obstruction to the overflow, by reducing the inflow. Moreover, the method of applying a cryoprobe to the conjunctival surface and freezing for 60 seconds without a thermocouple is crude, uncontrolled and likely to give unpredictable results.

Kirkness ${ }^{22}$ reviewed a small series of patients with advanced PKPG, managed with cycloablation using cryotherapy, who were all found to have a very poor result in the long term. Three out of 13 eyes had their pressure controlled for more than four years but none of these patients had clear grafts at the time of cyclocryotherapy. In the remainder, all either failed to be controlled or developed such severe complications that vision was lost.

At the same time a series of patients with similar diagnoses and degree of advanced PKPG were presented in whom silicone drainage tubing had been used to control IOP. ${ }^{23}$ Silicone drainage tubing was first described by Molteno ${ }^{24}$ in the management of advanced glaucoma after successful animal experiments. ${ }^{25}$ Later Schocket ${ }^{26}$ modified Molteno's technique replacing the acrylic plate which is sited in the orbit with an inverted silicone gutter (such as is used in retinal detachment surgery) encircling the eye. Schocket had used this method to control rubeotic glaucoma. Subsequently, with slight modifications, Molteno's and Schocket's designs have been used in the management of a variety of difficult glaucomas. ${ }^{27-30}$

One of the problems that was common no matter which technique was used was that prolonged hypotony and delayed expulsive haemorrhage were often found. Molteno modified his technique to a two stage process which was successful in reducing the incidence of these complications, ${ }^{31}$ but because of the relatively small surface area and consequently small surface area of fibrovascular 




Fig 2. The mean drop of IOP, following insertion of silicone drainage tube from time 0 , the pre-operative pressure. Values are plotted \pm standard errors. ${ }^{23}$ (Reproduced with the permission of the Editor of Eye).

sheath which developed around the plate, he was forced to use a complicated and potentially toxic antifibrotic regime to limit the degree of fibrosis produced. Dense avascular fibrous tissue does not absorb the aqueous well. The surface area is much larger in Schocket's method and there is less need to limit the degree of fibrosis.

Kirkness $^{32}$ was the first to use a two-stage Schocket-type tubing and also the first to report the use of silicone drainage tubing in the management of PKPG. He was able to demonstrate a mean pressure drop of at least $15 \mathrm{mmHg}$ which was sustained for up to four years after tube insertion (Fig 2). ${ }^{23}$ The need for a protective mechanism against the complication of expulsive haemorrhage has been very ably demonstrated recently by Canning. ${ }^{33}$ This study found that expulsive haemorrhage was particularly common after insertion of one-stage silicone tubes and in aphakic vitrectomised eyes. By preventing prolonged and profound hypotony the two-stage technique may help avoid this problem. The results from silicone drainage tubing are significantly superior to cyclocryotherapy in the management of advanced glaucoma once conventional drainage therapy has failed $(p=0.05)$. Figure 3 shows the comparative survival curves for maintenance of normal IOP and graft status after either cyclocryo or silicone tube. The curves are constructed according to the methods of Kaplan and Meier ${ }^{34}$ and represent the best means of following the success of a treatment regime where recruitment of patients to a study begins at differing times and where follow-up varies, (censored data). Statistical



Fig 3. The probability of maintenance of pre-operative graft status and normal intraocular pressure with time, comparing silicone drainage tubing and cyclocryotherapy. All grafts receiving tubes were clear at time of insertion, although two were showing signs of early endothelial decompensation. Although the follow-up of the cyclocryotherapy group is longer, the tube series has survived significantly better at $p=0.05^{23}$. (Reproduced with the permission of the Editor of Eye).

comparisons can be made by using an analysis described by Gehan. ${ }^{35}$ Data quoted without such statistical elaboration is of limited value, when considering long-term effects of differing treatment regimes. Following Kirkness' ${ }^{32}$ initial report, the use of a Molteno-type implant for PKPG has been reported by McDonnell ${ }^{36}$ but with shorter follow-up. The pressure reduction achieved was similar to Kirkness' but the complications produced were more frequent. In particular graft rejection was commonly encountered with five out of 17 eyes suffering irreversible rejection, presumably for the same reason as those in Kirkness' series. McDonnell's patients did not receive long term prophylactic topical steroid therapy. It is clear that the silicone drainage tubing can act as an additional limb of the graft rejection arc, ${ }^{37}$ presumably since the fibrovascular sheath which is in direct communication with the anterior chamber does not have any blood-eye barrier. In addition, if the tube has been inserted through a cyclodialysis cleft, it may irritate the ciliary body producing a low grade uveitis which can also promote an allograft rejection. This emphasises the need for long term topical steroid therapy in grafted patients with silicone drainage tubes.

\section{Conclusion}

Postkeratoplasty glaucoma remains one of the most serious and difficult to manage complica- 
tions which may occur following penetrating keratoplasty. Prevention is difficult but avoidance of predisposing factors may help. Cataract incisions through the clear cornea may limit conjunctival scarring and angle damage, making control easier should PKPG develop in the aphakic or pseudophakic eye. Awareness of the susceptible groups, may allow more rigorous supervision so early diagnosis may be made and prolonged periods of raised pressure may be avoided. The use of oversized donor buttons may help and when there is no contra-indication, some benefit may be gained.

A reliable and effective nonsteroidal immunsuppresive in topical form does not as yet exist although cyclosporin A has shown early promise. Such a development will help in the future and may make control easier in established PKPG. Refinements of surgical technique may make surgical measures to control the pressure more reliable. Appreciation of the relative risks and merits of the various forms of surgery available may permit survival of vision for longer in severely compromised eyes.

For the foreseeable future any surgeon undertaking corneal graft surgery must be prepared to cope with the problem of raised intraocular pressure in a sizeable proportion of his patients.

\section{References}

${ }^{1}$ Irvine AR, Kaufman HE. Intraocular pressure following penetrating keratoplasty, $A m \quad J$ Ophthalmol 1969; 68: 835-8.

${ }^{2}$ Schmeissar ET, Smith TJ. Flicker VEP frequency response curves in glaucoma. Invest Ophthalmol Vis Sci 1988; 29: 239.

${ }^{3}$ Maumenee AE. Clinical patterns of corneal graft failure. In: Corneal graft failure, Ciba Synposium 15, Elsevier Associated Scientific Publishers, Amsterdam 1973, p5-15.

${ }^{4}$ Olson RJ, Kaufman HE. Prognostic factors of intraocular pressure after aphakic keratoplasty. $\mathrm{Am}$ J Ophthalmol 1975; 86: 510-15.

${ }^{5}$ Zimmerman TJ, Krupin T, Grodzki W, et al. The effect of suture depth on outflow facility in penetrating keratoplasty. Arch Ophthalmol 1978; 96: 505-6.

${ }^{6}$ Zimmerman $\mathrm{TJ}$, Olson $\mathrm{RJ}$, Waltman $\mathrm{S}$, et al. Transplant size and elevated intraocular pressure. Arch Ophthalmol 1978; 96: 2231-3.

${ }^{7}$ Olson RJ, Kaufman HE. A mathematical description of causative factors and prevention of elevated intraocular pressure after keratoplasty. Invest Ophthalmol Vis Sci 1977; 16: 1085-92.
${ }^{8}$ Olson RJ. Aphakic keratoplasty. Determining donor tissue size to avoid elevated intraocular pressure. Arch Ophthalmol 1978; 96: 2274-6.

${ }^{9}$ Lass JH, Pavan-Langston D. Timolol therapy in secondary angle closure post penetrating keratoplasty. Ophthalmology 1979; 86: 51-9.

${ }^{10}$ Cohen EJ, Kenyon R, Dohlman CH. Iridoplasty for the prevention of post-keratoplasty angle closure and glaucoma. Ophthalmic Surg 1982; 13: 994-6.

${ }^{11}$ Bourne WM, Davidson JA, O'Falon WM. The effects of oversize donor buttons on postoperative intraocular pressure and corneal curvature in aphakic penetrating keratoplasty. Ophthalmology 1982; 89: 242-6.

${ }^{12}$ Perl T, Charlton KH, Binder PS. Disparate diameter grafting, astigmatism, intraocular pressure, and visual acuity. Ophthalmology 1981; 88: 774-81.

${ }^{13}$ Olson, RJ. Discussion (of Perl T, Charlton KH, Binder PS). Disparate diameter grafting, astigmatism, intraocular pressure, and visual acuity. Ophthalmology 1981; 88: 774-80 and 780-91.

${ }^{14}$ Kirkness CM. Penetrating keratoplasty in the management of suppurative keratitis. Developments in Ophthamology (Karger, Basel) (In Press).

${ }^{15}$ Thoft RA, Gordon JM, Dohlman CH. Glaucoma following keratoplasty. Trans Am Acad Ophthal Otolaryng 1974; 78: 352-9.

${ }^{16}$ Krupin TJ, Waltman S. Complications in ophthalmic surgery. Second edition. JB Lipincott and Co, 1984 pl13.

${ }^{17}$ Wright JE. The Bedford glaucoma survey in Glaucoma (Symposium). LB Hunt ed, E and S Livingstone, Edinburgh, 1966, p12-17.

${ }^{18}$ Wilson RP, Spaeth GL, Poryzees EM. The place of timolol in the practice of ophthalmology. Ophthalmology 1980; 87: 451-53.

${ }^{19}$ Van Meter WS, Allen RC, Waring III GO, Stulting RD. Laser trabeculoplasty for glaucoma in aphakic and pseudophakic eyes after penetrating keratoplasty. Arch Ophthalmol 1988; 106: 185-8.

${ }^{20}$ Casey TA, Gibbs D. Complications in corneal grafting. Trans Ophthalmol Soc UK 1972; 92: 517-30.

${ }^{21}$ Binder PS, Abel RA, Kaufman HE. Cycolcryotherapy for glaucoma after penetrating keratoplasty. Am J Ophthalmol 1975; 79: 489-92.

${ }^{22}$ Lemp MA, Pfister RR, Dohlman CH. The effect of intraocular surgery on clear corneal grafts. $A m J$ Ophthalmol 1970; 70: 719-21.

${ }^{23}$ Kirkness CM, Ling Y, Rice NSC. The use of silicone drainage tubing to control post-keratoplasty glaucoma. Eye 1988 (In Press).

${ }^{24}$ Molteno ACB. A new implant for glaucoma - clinical trial. Br J Ophthalmol 1969; 53: 606-15.

${ }^{25}$ Molteno ACB. A new implant for glaucoma - animal trial. Br J Ophthalmol 1969; 53: $161-8$. 
${ }^{26}$ Schocket SS, Lakhpal V, Richards RD. Anterior chamber tube shunt to an encircling band in the treatment of neovascular glaucoma. Ophthalmology 1982; 89: 1188-94.

${ }^{27}$ Schocket SS, Nirankai VS, Lakhpal V, et al. Anterior chamber tube shunt to an encircling band in the treatment of neovascular and refactory glaucomas; a long term study. Ophthalmology 1985; 92: 553-6.

${ }^{28}$ Sarkies NJC, Hitchings RA. Silicone tube and gutter in advanced glaucoma. Trans Ophthalmol Soc UK 1985; 104: 133-6.

${ }^{29}$ Brown RD, Cairns JE. Experience with the Molteno long tube implant. Trans Ophthalmol Soc UK. 1983; 103: 297-312.

${ }^{30}$ Krupin T, Podos SM, Becker B, Newkirk JB. Valve implants for filtering surgery. Am J Ophthalmology 1976; 81: 232-5.

${ }^{31}$ Molteno ACB, Ancker E, van Biljon G. Surgical technique for advanced juvenile glaucoma. Arch Ophthalmol 1984; 102: 51-7.
${ }^{32}$ Kirkness CM. Penetrating keratoplasty, glaucoma and silicone drainage tubing. Dev Ophthalmology (Karger, Basel) 1987; 14: 161-65.

${ }^{33}$ Canning CR, Lavin M, McCartney ACE, et al. Delayed suprachoroidal haemorrhage after glaucoma operations. Eye 1988 (In Press).

${ }^{34}$ Kaplan E, Meier P. Non parametric estimation from incomplete observations. J Am Statist Ass 1958; 53: $457-81$.

${ }^{35}$ Gehan EA. A generalised Wilcoxon test for comparing arbitarily singly censored samples. Bioemetrika 1965; 52: 202-3.

${ }^{36}$ McDonnell PJ, Robin JB, Schanzlin DJ, et al, Molteno Implant for control of glaucoma in eyes after penetrating keratoplasty. Ophthalmology 1988; 95: 364-9.

37 Jones BR. Present knowledge and problems of corneal graft failure in: Corneal graft failure, Ciba Synposium 15, Elsevier Associated Scientific Publishers, Amsterdam 1973, p349-54. 